\title{
Defenses in Interpersonal Interaction: Using a Theory-Building Case Study to Develop and Validate the Theory of Interpersonal Defense
}

\author{
MICHAEL A. WESTERMAN ${ }^{\text {a,b,c }}$
}

\author{
${ }^{\mathrm{a}}$ New York University \\ ${ }^{\mathrm{b}}$ Correspondence concerning this article should be addressed to: Michael Westerman, Department of Psychology, \\ New York University, 6 Washington Place, Room 451, New York, NY 10003. \\ Email: michael.westerman@nyu.edu \\ ${ }^{\mathrm{C}}$ I would like to express my thanks to J. Christopher Muran, Jeremy Safran, and Arnold Winston for giving me \\ access to data from the Brief Psychotherapy Research Project at Beth Israel Medical Center for the research reported \\ in this article.
}

\begin{abstract}
I investigated interpersonal defense theory, an interpersonal reconceptualization of defense processes, using the theory-building case study approach. Close examination of patient-therapist interaction during a psychotherapy session provided support for tenets of the theory. The analyses of the clinical material also elucidate some of the key concepts of interpersonal defense theory. Those concepts include a new way of conceptualizing the nature of problematic interpersonal behavior, which offers a novel approach to understanding patients' contributions to the alliance and transference phenomena. The analyses also clarify ideas from the theory about how defensive behavior on the part of one individual affects how the other person in a relationship behaves. These ideas lead to a new approach to countertransference, point away from common formulations of the self-fulfilling prophecy concept, and offer a novel response to the question of why dysfunctional processes persist. In addition to considering these substantive matters related to interpersonal defense theory, I also consider methodological issues related to the theory-building case study approach. The analyses presented illustrate the process of simultaneously examining whether multiple tenets from a theory are supported by observations on a single case, a crucial part of the theory-building case study approach that can make unique contributions to validating theories. I also discuss the role played by case formulations in the process of determining whether observations conform to theoretical tenets, which is an aspect of the logic of theory validation that has not been considered previously in the literature on the theory-building case study approach.
\end{abstract}

Key words: interpersonal defense; coordination; theory-building case study; self-fulfilling prophecy; maintenance of dysfunctional processes; clinical case studies; case studies

In this article, I present results from a theory-building case study of the theory of interpersonal defense. My objectives are two-fold. My first goal, which concerns substantive issues, is to offer some evidence that supports a number of the tenets of interpersonal defense theory and that clarifies key ideas from the theory by showing how they apply in an actual case. 
Defenses in Interpersonal Interaction: Using a Theory-Building Case Study to Develop and Validate the Theory of Interpersonal Defense

M.A. Westerman

Pragmatic Case Studies in Psychotherapy, http://pcsp.libraries.rutgers.edu

Volume 7, Module 4, Article 3, pp. 449-476, 12-12-11 [copyright by author]

My second goal, which concerns methodology, is to illustrate the theory-building case study approach and to identify and discuss some aspects of its logic that have not been considered previously in the literature.

\section{INTERPERSONAL DEFENSE THEORY}

The central guiding idea in interpersonal defense theory (Westerman, 1998; Westerman \& Steen, 2007, 2009) goes back to Freud. He recognized that although individuals employ processes of defense in the attempt to prevent dreaded outcomes, those defense processes themselves actually lead to psychological problems. For the most part, psychoanalytic theory incorporates this core insight in a manner that focuses on what is typically called the "inner" realm. ${ }^{1}$ According to that viewpoint, defenses are intrapsychic processes (i.e., the ego mechanisms of defense) that aim at regulating internal states (anxiety, guilt, and, in more recent theorizing, self-esteem). Interpersonal defense theory is based on the core insight, but it offers an interpersonal reconceptualization of defense processes. According to this reconceptualization, primarily, defenses are interpersonal behavior patterns of a certain kind. Individuals employ these behavior patterns to influence what happens in their interpersonal relationships, specifically, how the other person in a relationship acts toward them.

Interpersonal defense theory is informed by several sources within psychology and psychiatry, including the interpersonal theorists (Horney, 1939, 1945; Sullivan, 1953), Wachtel's theory of cyclical psychodynamics $(1994,1997,2008)$, and communications theory (Watzlawick, Beavin, \& Jackson, 1967). It also is informed by the contributions of a number of philosophers who place the person first-off in the world of concretely meaningful practical activities, including Merleau-Ponty (1962), Wittgenstein (1958), Heidegger (1962), and the pragmatists (e.g., Dewey, 1896). In developing the theory, I also have drawn upon discourse analysis, especially work on developmental pragmatics in sociolinguistics (e.g., Keenan \& Schieffelin, 1976). The discourse analytic method I employ provides a way to conceptualize and study interpersonal processes in terms of complex patterns in how individual behaviors are organized over time. It will become evident in what follows that closely examining the organization of interaction over time occupies a central place in my approach. I should note that I also employ Benjamin's (e.g., 1979) Structural Analysis of Social Behavior for characterizing the interpersonal processes of interest.

Interpersonal defense theory includes a number of tenets. Some of the main tenets concern (a) the nature of defensive interpersonal behavior patterns, (b) how interpersonal defenses represent attempts to influence whether wished-for and feared outcomes will occur in

\footnotetext{
${ }^{1}$ The internal-external dichotomy appears throughout the discipline of psychology, but I believe it is deeply misguided. Although some readers may think that what I go on to say about interpersonal defense in this article represents a shift to the "external" side of this polarity, the theory actually departs from both sides of the all too familiar dichotomy (see Westerman \& Steen, 2007.)
} 
Defenses in Interpersonal Interaction: Using a Theory-Building Case Study to Develop and Validate the Theory of Interpersonal Defense

M.A. Westerman

Pragmatic Case Studies in Psychotherapy, http://pcsp.libraries.rutgers.edu

Volume 7, Module 4, Article 3, pp. 449-476, 12-12-11 [copyright by author]

interpersonal relationships, (c) the complex set of outcomes that actually result from interpersonal defenses, and (d) how these processes appear in the therapeutic relationship. The case study analysis I will present shortly examined these tenets. At this juncture, I will offer succinct statements of the tenets that will be examined. The remarks I offer later when I consider whether the clinical data support each of those tenets will clarify what the tenets mean by discussing them at some length and, especially, by offering concrete clinical illustrations of each point.

The tenets to be examined include the following:

1. Defensive interpersonal behavior patterns are characterized by recurring failures of coordination, i.e., contributions to an interaction do not mesh with the other person's bids or with bids made by the person him- or herself at other points in time.

2. A person's noncoordinating pattern often (not always) appears across his or her different relationships, including the therapeutic relationship if the person is in therapy (reconceptualization of transference).

3. These patterns represent attempts to negotiate conflicts between pursuing wished-for relationship outcomes and feared consequences that might occur if a person pursues his or her wished-for outcomes.

4. The patterns include elements aimed at realizing the wish and other elements that are attempts to make impossible feared consequences that might occur as the result of pursuing the wish.

Tenets 5-9 are about the feed-forward effects of defensive interpersonal behavior, that is, they concern the ways in which defensive patterns actually affect what happens in interpersonal relationships:

5. The feed-forward effects delineated in tenets 6-9 with regard to relationships in general often occur in the therapy situation in particular (reconceptualization of countertransference).

6. Defensive behavior reduces the likelihood that instances of the person's main feared consequences will occur (in contrast to the concept of a self-fulfilling prophecy).

7. Defensive behavior makes it less likely that occurrences of the person's main wished-for outcomes will take place.

8. Defensive behavior makes it more likely that certain negative outcomes will occur that are distinct from the individual's key feared consequences.

9. Defensive behavior leads to certain positive outcomes that are distinct from the individual's key wished-for outcomes.

Although I will discuss all of these tenets at length at later points of this paper, I can note here that the tenets about the feed-forward effects of defensive behavior provide the basis for a novel response to the longstanding question about why dysfunctional processes persist. I will elaborate on this point in the context of my analysis of material from a case and comment on how my answer to this question differs from the responses offered based on other approaches to psychopathology. I should also note that interpersonal defense theory includes other tenets about 
Defenses in Interpersonal Interaction: Using a Theory-Building Case Study to Develop and Validate the Theory of Interpersonal Defense

M.A. Westerman

Pragmatic Case Studies in Psychotherapy, http://pcsp.libraries.rutgers.edu

Volume 7, Module 4, Article 3, pp. 449-476, 12-12-11 [copyright by author]

how to reconceptualize the role played by the intrapsychic ego mechanisms of defense (these processes are included in the theory) and what contributes to good therapeutic outcomes. Those tenets, however, are not the subject of this paper, which focuses on what the theory has to say about what problematic interpersonal processes are like and the effects they have on what transpires in relationships.

\section{THEORY-BUILDING CASE STUDY APPROACH}

Prior to the efforts I discuss in this paper, my work on developing the theory of interpersonal defense was based on my clinical experience, observational studies of patient interpersonal behavior in psychotherapy (e.g., Westerman \& Foote, 1995; Westerman, Foote, \& Winston, 1995) and experimental studies with normal subjects (Dahmen \& Westerman, 2007; Westerman \& Prieto, 2006; Westerman \& Steen, 2009). More recently, I realized that a promising way to proceed with this work would be to conduct theory-building case studies, following an approach developed by Stiles (2003, 2007, 2009).

Stiles has argued convincingly that case studies should not be limited to the discovery phase of research; they can make significant contributions to theory validation if they are pursued in a particular manner. In fact, Stiles maintains that, in certain respects, case studies are superior to hypothesis-testing studies when it comes to the justification phase of research. One strength of theory-building case studies is their sensitivity to context. Another strength is that when an investigator conducts theory-building case study research, he or she can simultaneously compare observations on a single case to multiple tenets of a theory, whereas a hypothesistesting investigation focuses on a single theoretical tenet. This point is quite important. As Stiles has pointed out, one way to think about this advantage of theory-building case studies is that simultaneously comparing observations to multiple tenets offers a powerful challenge to a theory because there are few degrees of freedom. Indeed, it would be extremely difficult to invent raw data which would simultaneously conform to the multiple tenets of a theory that includes even a modest number of tenets. Therefore, if data from a real case support all the tenets of a theory, this provides compelling support for the theory.

The theory-building case study approach also includes another component. When an investigator employs the approach, he or she may discover that observations from a case do not conform to a tenet. At a juncture of this kind, the investigator can revise the tenet to make possible a better fit with the observation. The researcher subsequently examines further observations to see if they provide support for the new version of the tenet.

In sum, the theory-building case study approach can contribute to validating and developing theories. With regard to theory validation, it can provide an especially compelling kind of confirmation of theoretical tenets. With respect to theory development, it offers a method that can lead to refining and elaborating a theory.

I decided to employ the theory-building case study approach in my own research on interpersonal defense theory for several reasons. For one thing, I realized that because the 
Defenses in Interpersonal Interaction: Using a Theory-Building Case Study to Develop and Validate the Theory of Interpersonal Defense

M.A. Westerman

Pragmatic Case Studies in Psychotherapy, http://pcsp.libraries.rutgers.edu

Volume 7, Module 4, Article 3, pp. 449-476, 12-12-11 [copyright by author]

approach involves carefully examining phenomena of interest in context, it could help me arrive at a clearer understanding of what the processes of interest are like as compared to the other methods I previously employed. For the same reason, I realized that the methodology would yield examples of the phenomena so that I could more effectively explain the theory's points to other researchers and clinicians. I also recognized the value of determining whether multiple theoretical tenets are simultaneously supported by observations from a case and the usefulness of employing an approach that was well-suited for revising and elaborating the tenets I had previously developed.

\section{CASE STUDY}

I now turn to analyzing material from a case. The material is from a treatment that is part of a multiple case study project I have conducted. In turn, the small set of cases that are the basis for that project are from a large-scale, nomothetic study of psychotherapy. I will refer to that study as the "umbrella investigation." In what follows, I briefly describe the umbrella investigation and the multiple case study project, then introduce the case that is the focus of this paper, and then turn to analyzing material from that case.

\section{Larger Research Context}

The umbrella investigation was a study of the effects of three brief treatments for patients with personality disorders (Muran, Safran, Samstag, \& Winston, 2005). The patients $(\mathrm{N}=128)$ had diagnoses of Cluster $C$ personality disorders (avoidant, obsessive-compulsive, dependent, and self-defeating ${ }^{2}$ personality disorders) or personality disorder, not otherwise specified (PD NOS). The great majority of patients also had Axis I diagnoses. I selected the cases for my multiple case study project from one of the three treatment conditions included in the umbrella investigation. That therapy approach, which is called short-term dynamic therapy (Pollack, Flegenheimer, Kaufman, \& Sadow, 1992), is similar to the brief psychodynamically-oriented therapies developed by Luborsky (1984) and Strupp and Binder (1984). Like the other treatment conditions in the umbrella investigation, the short-term dynamic therapy condition was conducted as a 30-session brief treatment with sessions taking place once per week.

Following guidelines for what has been called the research-informed approach to case studies (Soldz, 1990), I selected cases for the multiple case study project using a set of criteria based on quantitative measures from the umbrella investigation. In particular, I employed the case comparison method (Strupp, 1980a, 1980b, 1980c, 1980d) of identifying pairs of cases treated by the same therapist in which one case had a good outcome and the other case had a poor outcome. Muran et al. (2005) used scores on their study's outcome measures (which included both patient self-report measures and clinician assessments) to determine whether a

\footnotetext{
${ }^{2}$ Self-defeating personality disorder was one of the Cluster C diagnoses in DSM-III-R, which was the classification system in use when the umbrella investigation was conducted.
} 
given patient showed "clinically significant” improvement on each measure. I treated patients who showed clinically significant improvement on three or more of five outcome measures as having had a "good" outcome and patients who showed clinically significant on zero or one of the fives measures as having had a "poor" outcome. Using these criteria, I selected two pairs of cases for the multiple case study project. One pair of these cases had been treated by one therapist and the other pair had been treated by a different therapist.

\section{The Case}

This paper presents an analysis of material from one of the cases in the multiple case study project. The patient was a 33-year-old female. ${ }^{3}$ Her target complaints (Battle et al., 1966), which were assessed as part of the umbrella investigation, included self-esteem issues, relationship problems, and feelings of inadequacy at work/concerns about not making progress in her career. Her diagnosis based on a SCID interview (Spitzer, Williams, Gibbon, \& First, 1990) that was conducted as part of the umbrella investigation included dysthymia and social phobia on Axis I and self-defeating personality disorder and PD NOS on Axis II. The therapist was a doctoral level male psychologist. At the time this therapy took place, he had 8 years of experience, including prior training and experience using the short-term dynamic therapy approach. The case met the criteria described above for "poor" outcome. The therapy resulted in clinically significant change on only one of the five outcome measures.

\section{Clinical Material}

In what follows, I carefully examine a short segment of patient-therapist interaction from an early session of the case. By doing so, I illustrate how it is possible to scrutinize clinical data from a case to see if it conforms simultaneously to a number of theoretical tenets - in this study, the nine tenets from interpersonal defense theory listed above. I should note one point here that I will return to at greater length later in the paper: Although the brief segment of interaction to be analyzed includes observations related to the entire set of tenets under consideration, any small amount of data can only increase our confidence in theoretical propositions to a limited extent. To be sure, the process of validating a theory requires determining whether many such observations from a given case as well as data from other cases support the theory.

The segment comes from the fourth session of the case. ${ }^{4}$ To set the stage, I can note that

\footnotetext{
${ }^{3}$ I have altered some details in my description of the case to make sure that it includes no information that would make it possible to identify the patient.

${ }^{4}$ I commented briefly on this segment in a previous article (Westerman, 2009). Here, I present much more extensive consideration of the clinical material. The analysis I offer in what follows is far more detailed and it is more complete in the sense that it includes examination of a larger set of the tenets of interpersonal defense theory.
} 
Defenses in Interpersonal Interaction: Using a Theory-Building Case Study

to Develop and Validate the Theory of Interpersonal Defense

M.A. Westerman

Pragmatic Case Studies in Psychotherapy, http://pcsp.libraries.rutgers.edu

Volume 7, Module 4, Article 3, pp. 449-476, 12-12-11 [copyright by author]

the exchange occurred near the beginning of the session. The session began with the patient saying that she did not want to come to therapy that day. Then, she touched quickly on a few ideas about why she felt that way. At two points, the therapist asked if the patient's feelings about attending the session were related to anything he did, but the patient did not address those inquiries. Then, at the beginning of the segment to be analyzed, the patient gave a reason for not wanting to attend the session saying that she did not like the person she was showing the therapist. The transcript that follows begins with that contribution to the interaction and then continues from that point:

(1) Patient: .... And also I feel like I don't like myself here. (smiles) I don't like the person I'm showing you really I um (pause)//

(2) Therapist: // (interrupts) what's not to like?

(3) Patient: I just feel like I'm (pause) insecure and (pause) (clears throat) (pause) we're back to that weakness thing again I guess, but uh (pause) I don't think that I present um (pause) //

(4) Therapist: // (interrupts) (smug smiling) finish that. You don’t think you present

(5) Patient: uh (dips head down, smiling coyly) (pause) the any of my strengths. I mean I, uh, I (pause) cause I get easily flustered and sometimes (pause) I get lost with you, um, because I feel pressured and//

(6) Therapist: // (interrupts) what is it? Are there things that I'm doing that are contributing to that feeling of pressure?

(7) Patient: (pause) um (looks down, looks at therapist, smiles) (pause) probably (laughs)

(8) Therapist: okay (smiling)

(9) Patient: oh goodness (smiling), uh//

(10) Therapist: // (interrupts) (smiles) I mean besides things like asking you to finish the sentence or something when you when you start (pause) resisting a thought that you had in your mind. (pause) Are there other things that I that you can think of that I do that, you know, make it difficult for you?

(11) Patient: (pause) (sighs) (pause) I can’t put my finger on it.

\section{Analysis}

\section{Tenet 1}

According to the first tenet, defensive interpersonal behavior patterns are characterized by recurring failures of coordination, that is, contributions to an interaction do not mesh with the other person's bids and with bids made by the person him- or herself at other points in time. The question of whether the patient interacts with the therapist in this exchange in a defensive 
Defenses in Interpersonal Interaction: Using a Theory-Building Case Study to Develop and Validate the Theory of Interpersonal Defense

M.A. Westerman

Pragmatic Case Studies in Psychotherapy, http://pcsp.libraries.rutgers.edu

Volume 7, Module 4, Article 3, pp. 449-476, 12-12-11 [copyright by author]

manner will have to wait until we consider the other tenets but, at this point, we can ask whether her behavior in the segment is characterized by recurring failures of coordination. The answer to that question is "yes." Her bids in the interaction do not mesh with the therapist's contribution or with her own contributions at other points in time. Before I point out the patient's coordination breaches by carefully examining each turn of the exchange, I can offer a general characterization of her noncoordinating pattern of behavior: She repeatedly puts something forward and then does not follow through. Often, she fails to follow through as if she is unable to continue discussion of the point she offered. Furthermore, when she puts something forward, she often does this with a contribution that is just an allusion to some point that doesn't say much at all about that point. Also, when she puts something forward, she often does so in a manner that derails discussion of the topic that was on the table. Such contributions mesh neither with the therapist's prior bids nor with her own previous contributions. Therefore, whether we look forward or backward from any contribution of this sort, we see failures of coordination - looking forward, we see that the patient does not follow through with the new topic she begins to talk about, and looking backward, we see that her bids that put something on the table derail the previous discussion.

The first example of this pattern occurs in the first turn of the transcript. In that turn, the patient initiates a new topic ("I don't like myself here") and then trails off with a long pause. To be sure, we should not make much of this one instance of "trailing off." It is merely a single instance and it is understandable that the patient might well find it difficult to talk about how she doesn't, as she put it, "like myself here.” In order to determine whether there is a recurring pattern, we need to see how (and whether) things develop. In turn 2, the therapist encourages the patient to say more about her comment about not liking the way she is in therapy. In turn 3 , the patient expands a little on the topic by referring to a closely related point the two talked about previously ("we're back to that weakness thing again I guess"), but she trails off again with another long pause.

Once again, in turn 4, the therapist tries to get the patient to expand on her allusion to not liking the way she "presents" in therapy. (Note that I will discuss the nature of the therapist's bids at a later point.) The patient's response in turn 5 is very interesting. She begins by responding for a moment to the therapist's coaxing (by saying that she doesn't present "any of my strengths"), but then she hesitates and derails further consideration of the topic that she put forward (i.e., not liking how she is in therapy) by going back to the topic from earlier in the session about the therapist's role. Specifically, she alludes to a positive response to the question the therapist asked prior to the transcribed segment about whether her feelings about coming to therapy are related to anything he did (by saying, "I get lost with you, um, because I feel pressured). Here, it is important to recognize that with these remarks the patient actually contributes more to that earlier topic than she did earlier in the session when the therapist asked her about it directly (again, prior to the transcribed segment), which raises a question about whether her failure to follow through at many points in the exchange actually is due to the patient being unable to do so.

Nevertheless, interactions certainly are not lock-step procedures and we should entertain the possibility that, although the patient departs from the current topic of not liking how she is in 
Defenses in Interpersonal Interaction: Using a Theory-Building Case Study to Develop and Validate the Theory of Interpersonal Defense

M.A. Westerman

Pragmatic Case Studies in Psychotherapy, http://pcsp.libraries.rutgers.edu

Volume 7, Module 4, Article 3, pp. 449-476, 12-12-11 [copyright by author]

therapy (which she herself opened up) in turn 5 by shifting to talk about the earlier topic of the therapist's role, she may be ready now to talk about that prior topic. Furthermore, one might argue that the topic of the therapist's role has some relevance to the topic of how the patient does not feel good about the way she is in therapy because it could be viewed as the reason the patient behaves in a way she does not feel good about. But this reading is not borne out by what follows. It quickly becomes clear that the patient also is not ready to talk about the topic of the therapist's role. Even though the therapist goes along with the patient's shift of topic in turn 6 by asking her to say more about his role, the patient responds by merely alluding to a positive answer to the therapist's question of whether he is contributing to her feeling pressured by saying "probably" while smiling and laughing in turn 7 and then saying “oh goodness” in turn 9 while smiling and then hesitating rather than continuing. In turn 10, the therapist tries to get the patient to add something to her allusions to a positive response, but in turn 11, the patient only says “I can't put my finger on it" and, thereby, fails to follow through with the new topic she herself entered into the discussion in turn 5 - which itself, derailed discussion of the topic about how the patient feels about herself in therapy, which she herself had put on the table in turn 1.

\section{Tenet 2}

According to the second tenet, a person's noncoordinating pattern often appears in many of his or her relationships, including the therapeutic relationship if the person is in therapy. This tenet provides a reconceptualization of the transference concept that (a) shifts from a focus on internal processes (distorted perceptions motivated by unresolved internal conflicts) to interpersonal behavior patterns, and (b) offers the specific notion that, for a given individual, transference involves the appearance across relationships of interpersonal behavior characterized by a particular noncoordinating pattern.

The session segment under consideration offers support for the second tenet because the noncoordinating pattern that characterizes how the patient engaged with the therapist in that interaction is similar to her behavior in other relationships. For example, while she was in therapy, the patient met a man in an adult education class. They spent some time talking during breaks in class meetings and they also had some phone conversations. Then on one occasion when they were talking on the phone, the patient told this fellow that she wanted him to show her more attention when they were in class, a remark that we can view as an "allusion" to a wish for a closer relationship. The man was more attentive at the next class meeting, but the patient behaved in a distant manner. This parallels the instances in the therapy segment I referred to as failures of following through. At that meeting of the class, the patient did not show interest in what this fellow talked to her about during the breaks and she spent time with other male members of the class. Therefore, her failure to follow through along the lines of her initial "allusion" (her remark on the phone about how she would like the man to show her more attention) also seemed to allude to something else, such as being disappointed with the man she had begun to get to know or being interested in another man in the class. Hence, she derailed one line of exchange (the one she began with her remark on the phone) by not following through and also by behaving in a way that seemed to open up some new topic, although she did that by merely alluding to something else, not clearly putting something new on the table for the man to 
Defenses in Interpersonal Interaction: Using a Theory-Building Case Study

to Develop and Validate the Theory of Interpersonal Defense

M.A. Westerman

Pragmatic Case Studies in Psychotherapy, http://pcsp.libraries.rutgers.edu

Volume 7, Module 4, Article 3, pp. 449-476, 12-12-11 [copyright by author]

respond to. In these respects as well, what happened parallels the pattern of the patient's behavior in the session segment.

\section{Tenets $3 \& 4$}

Why does the patient behave the way she does in the therapy session segment we are considering and in other relationships as well? I can begin to answer that question by turning to the third and fourth tenets, which state that the recurring failures of coordination that characterize defensive interpersonal behavior patterns represent attempts to negotiate conflicts between pursuing wished-for relationship outcomes and feared consequences that might occur if a person pursues his or her wished-for outcomes (tenet 3), and that defensive interpersonal patterns include elements aimed at realizing the wish and other elements that are attempts to make impossible feared consequences that might occur as the result of pursuing the wish (tenet 4). The segment of interaction under consideration provides supports for the third tenet and for a revised version of the fourth tenet. I will offer a detailed discussion of the process of revising tenet 4 at a later point in this paper. At this juncture, I will show that the segment provides support for part of the original version of tenet 4 - defensive patterns are structured in such a way that they aim at realizing an individual's wish while they also attempt to make impossible feared consequences that might occur as the result of pursuing the wish. The revised tenet differs from the original only in that it no longer links specific elements of the pattern to pursuing the wish and different elements of the pattern to avoiding the fear (more later).

In order to determine whether the segment provides support for tenet 3 and the part of tenet 4 noted above, it is necessary to arrive at a formulation of the patient's wish and fear. For this purpose, I have found that it is very helpful to use the conceptual scheme and vocabulary provided by Benjamin's (e.g., 1979) Structural Analysis of Social Behavior (SASB). Figure 1 presents the parts of the SASB model that are relevant to the present analysis. Although the model is complicated, for present purposes, the key points are the following: The two parts of the figure are referred to as "surfaces." As shown here, the figure includes the two interpersonal surfaces only and omits what is called the introject surface. The upper part of the figure (Interpersonal-Other, behaviors 110-148) is the "transitive" surface. It provides a scheme for characterizing how one person acts on the other. The lower part of the figure (Interpersonal-Self, behaviors 210-248) is the "intransitive" surface. It provides a way to describe how one person reacts to the other. Both surfaces are circumplexes that include an "affiliation" dimension (horizontal axis) and an "interdependence” dimension (vertical axis). The affiliation dimension runs from positive (on the right) to negative (on the left). The top end of the interdependence axis is characterized by behaviors that endorse the other person's freedom (transitive surface) or react in a free manner vis a vis the other person (intransitive surface). The bottom end of the interdependence axis is characterized by behaviors that manage/control the other person (transitive surface) or that yield to managing/controlling efforts by the other person (intransitive surface).

The SASB system includes its own set of tenets or postulates. One of those tenets is relevant to the discussion that follows. According to the SASB system, a behavior by one person 
Defenses in Interpersonal Interaction: Using a Theory-Building Case Study to Develop and Validate the Theory of Interpersonal Defense

M.A. Westerman

Pragmatic Case Studies in Psychotherapy, http://pcsp.libraries.rutgers.edu

Volume 7, Module 4, Article 3, pp. 449-476, 12-12-11 [copyright by author]

tends to evoke "complementary" behavior by the other person, although this certainly does not happen all of the time. Two behaviors are complementary if (a) one is on the transitive surface and the other is on the intransitive surface, and (b) they are located at the same point on their respective surfaces. For example, if one acts toward the other (transitive surface) by offering "sensible analysis" (point 144 on the figure), that increases the likelihood that the other person will react (intransitive surface) with “accept reason” (point 244).

Using the SASB system as my conceptual scheme, I arrived at a formulation of the patient's wishes and fears by carefully considering an extensive set of materials about the case. Those materials included information about the patient's early history in her family of origin that the patient provided on pencil-and-paper instruments completed at intake. I also considered the narratives the patient offered in sessions about current and past relationships and observations of her in-session behavior with the therapist. Based on these sources, I determined that the patient's wish was to be confirmed as ok as is (113) and to be shown empathic understanding (114), and that her fear was that if she pursued her wish, others would ignore her/pretend she was not there (126) and neglect her interests and needs (125).

One reason I use the SASB system is that it provides a way to characterize wishes and fears in terms of how significant others will behave, rather than how the individual in question will feel. For example, the latter approach might lead to formulating a particular patient's fear as “feeling inadequate," but this would leave open the question of whether that patient's feelings of inadequacy are linked, for example, to significant others attacking (130), forgetting about (127), or intruding on (137) him or her, or indeed whether the patient's fears about feeling inadequate are tied to any concerns about how significant others might act towards him or her. Interpersonal defense theory does include consideration of such "inner" experiences as feelings of inadequacy, but it views these phenomena as playing a role within defensive interpersonal behavior patterns that primarily aim at negotiating conflicts between wishes and fears understood in terms of how significant others act towards an individual (see Westerman \& Steen, 2007).

We can now return to the tenets under consideration, tenet 3 and the part of tenet 4 noted earlier. Does the clinical data support those claims? According to them, the patient's recurring failures of coordination should represent attempts to negotiate conflicts between pursuing her wished-for relationship outcomes, on the one hand, and, on the other, consequences that she fears might occur if she pursues her wished-for outcomes. In particular, her noncoordinating behavior pattern should be structured in such a manner that it aims at realizing her wish while it also attempts to make impossible feared consequences that might occur as the result of pursuing the wish. Does the patient's pattern of putting something forward (often as an allusion and often in a manner that derails discussion of the topic that was on the table) and then not following through conform to these ideas from interpersonal defense theory?

There is a very good fit with the clinical data here. Note that in order to pursue her wish that the other person - the therapist in the interaction segment we are considering - will confirm her as ok as is (113) and show empathic understanding (114), the patient would enthusiastically show herself (213) and clearly express herself (214) because those behaviors are the 
Defenses in Interpersonal Interaction: Using a Theory-Building Case Study to Develop and Validate the Theory of Interpersonal Defense

M.A. Westerman

Pragmatic Case Studies in Psychotherapy, http://pcsp.libraries.rutgers.edu

Volume 7, Module 4, Article 3, pp. 449-476, 12-12-11 [copyright by author]

complements of her wished-for responses. However, if she behaved in those ways, the therapist might behave in the manner she fears by ignoring (126) or neglecting her (125). ${ }^{5}$

The patient's noncoordinating pattern represents an attempt to negotiate this conflict. She partially expresses herself (214)/shows herself (213), but repeatedly fails to proceed further with her initial bids along those lines, often in ways that seem to indicate that she is unable to do so. In other words, she behaves in a manner that only "sort of" is described by the 214 and 213 SASB codes. Really expressing/showing oneself is not something a person can do in a single turn, e.g., by alluding to something - even if one alludes to something significant - or even by making a single substantial comment about something important. Instead, actually expressing/showing oneself requires putting on the table something about oneself and then following through if and when the other person shows interest. The upshot is that the patient behaves in a way that repeatedly includes attempts to realize her wish (by putting forward individual points or making allusions, albeit only putting forward individual points or making allusions) and that provides a way for her to avoid her fear because she never really expresses/shows herself.

\section{Tenet 5}

The part of tenet 4 that I discussed above maintains that defensive interpersonal patterns are attempts by people to influence what happens in their relationships with respect to wished-for and feared outcomes. The remaining tenets are about how an individual's defensive behavior actually affects how the other person in a relationship behaves. These feed-forward effects are delineated in tenets 6 through 9 . According to tenet 5, the feed-forward effects described in those tenets about relationships in general often occur in the therapy situation in particular. This constitutes a reconceptualization of countertransference because the "other person" in the therapeutic relationship is the therapist.

In certain respects, interpersonal defense theory offers a view of countertransference phenomena that is similar to previous accounts. Those approaches typically emphasize either how the patient "pulls" for certain reactions from the therapist or how the therapist's own unresolved issues may lead him or her to behave in problematic ways towards a patient. Interpersonal defense theory primarily focuses on the former idea, but it recognizes that therapists do not always behave in the ways their patients pull for and that whether they do will depend on how a given patient's behavior relates to the therapist's own defensive pattern. The key point of divergence from other approaches to countertransference is that the tenets about

\footnotetext{
${ }^{5}$ Although it might be argued that it is unlikely that any therapist would ignore or neglect a patient, (a) the patient certainly could be afraid that this outcome might occur no matter how unlikely it is, and (b) therapists can and do neglect and ignore their patients, even though this does not take an obvious form (e.g., staring out the window, falling asleep) very often, but rather typically appears in more subtle ways (see the hypothetical examples I offer later when I discuss tenet 6.)
} 
Defenses in Interpersonal Interaction: Using a Theory-Building Case Study

to Develop and Validate the Theory of Interpersonal Defense

M.A. Westerman

Pragmatic Case Studies in Psychotherapy, http://pcsp.libraries.rutgers.edu

Volume 7, Module 4, Article 3, pp. 449-476, 12-12-11 [copyright by author]

feed-forward effects in interpersonal defense theory offer a very specific and novel model of how a particular patient's defensive behavior might affect his or her therapist.

In what follows, I consider whether the session segment provides support for the tenets about feed-forward effects. My examination of those tenets focuses directly on countertransference phenomena because I examine how the patient's behavior influenced the therapist's behavior.

\section{Tenet 6}

According to tenet 6, defensive interpersonal behavior patterns make it less likely that instances of an individual's key feared consequences will occur. In other words, defensive behavior not only represents an attempt to avoid feared relationship events, as I discussed earlier, but it is also the case that defensive behavior typically succeeds at avoiding those outcomes. When a person pursues wished-for responses in an interaction, this opens up the possibility that responses they fear might occur instead. Defensive behavior patterns negotiate such conflicts by pursuing wished-for outcomes in ways that largely "cancel out" the possibility that the feared consequences will take place.

The session segment supports tenet 6 . The therapist did not ignore or neglect the patient. Indeed, he was very engaged in his interaction with her. As I commented briefly at an earlier point, the patient's interpersonal pattern works against her feared outcome because she never really expresses/shows herself. It is very unlikely that the therapist will ignore or neglect the patient as she pursues her wish, because she doesn't fully pursue her wish. In order for the patient to do that (fully pursue her wish), she would have to express/show herself, but she only makes very partial efforts along those lines. She puts ideas on the table or makes allusions, but she doesn't follow through. This cancels out consequences that might result if she did follow through on the individual points she puts forward.

I can illustrate this phenomenon by comparing the patient's actual behavior in turn 5 with a hypothetical scenario. In turn 5 of the actual interaction, the patient continues what she was saying in turn 4 ("I don't present”) by saying "any of my strengths," but then shifts the topic to how she feels pressured by the therapist. Imagine a hypothetical scenario in which the patient does not shift the topic in turn 5 but goes on to say in that turn that when she is not in a session, she has thoughts about the issues she and the therapist talk about, but then when she is in a session and thinks about bringing up some of those thoughts, none of them seem like good ideas after all. Imagine also that the patient goes on to say that the same thing happens to her at meetings at work.

A response of this sort certainly would represent following through on her actual comment about not presenting any of her strengths. She would be expressing or showing herself to the extent that one can do that in any single turn that follows up on another turn. Note, however, that this would open up the possibility that the therapist might ignore or neglect her. For example, he might show little interest in what she says, perhaps by saying "Oh, I see” and 
Defenses in Interpersonal Interaction: Using a Theory-Building Case Study to Develop and Validate the Theory of Interpersonal Defense

M.A. Westerman

Pragmatic Case Studies in Psychotherapy, http://pcsp.libraries.rutgers.edu

Volume 7, Module 4, Article 3, pp. 449-476, 12-12-11 [copyright by author]

then not saying anything further (i.e., the therapist might not follow through), or by simply saying "That sometimes happens for people in therapy" and then changing the topic.

Alternatively, the therapist's "response" might solely be to change the topic in a subtle way. He might ask the patient whether she has been worrying about work a lot lately or how things are going at work (e.g., “That reminds me. You haven't said anything about work in a while. How are things going there?”). These examples are subtle forms of ignoring or neglecting the patient, because although the therapist would be commenting on one part of something she says, he would be missing the crucial part of her contribution.

All of these hypothetical scenarios contrast with what actually occurs. In the actual interaction, the patient does not go on to follow through with a substantial comment (as in our hypothetical example in which she talks about how she comes up with ideas on her own, but then feels that they aren't good when she is in a situation with others). Therefore, she does not give the therapist the opportunity to ignore or neglect a contribution in which she expresses/shows herself.

\section{Tenet 7}

Although tenet 6 asserts that there are benefits to behaving defensively in the sense that such behavior makes it less likely that feared consequences will occur, the feed-forward effects of defensive patterns are quite complicated. Interpersonal defense theory also includes claims about the costs of defensive interpersonal behavior patterns. Tenet 7 marks out one aspect of those costs. As I said earlier, defensive behavior patterns include attempts to realize wishes. However, according to tenet 7, defensive interpersonal behavior patterns actually make it less likely that occurrences of key wished-for outcomes will take place.

The interaction we are considering supports this tenet. I noted previously that in the session segment, the patient behaves in a way that includes repeated attempts to realize her wish. By putting individual points on the table or making allusions, she does something like expressing/showing herself, and expressing and showing oneself are the complements of the patient's wish to be confirmed as ok as is or shown empathic understanding. However, because the patient does not follow through, that is, because she only puts forward individual points or makes allusions, she never really expresses/shows herself. This makes it highly unlikely that the therapist will behave in the wished-for manner. In other words, the possible impact of the attempts at realizing the wish largely gets cancelled out. In fact, the therapist responds in ways that do not confirm the patient as ok as is or show her empathic understanding.

Once again, let's compare the actual interaction to a hypothetical scenario in which the patient does not shift the topic in turn 5 , but goes on to tell the therapist that when she is not in a session she has thoughts about the issues she and the therapist talk about, but then feels that none of those ideas are good enough when she thinks about bringing them up in a session. As before, let's imagine that she also says that the same thing happens to her when she is at meetings at work. In this hypothetical scenario, the patient really expresses/shows herself. Although, as I noted above, the therapist might respond to her by ignoring or neglecting her, it is also the case 
Defenses in Interpersonal Interaction: Using a Theory-Building Case Study to Develop and Validate the Theory of Interpersonal Defense

M.A. Westerman

Pragmatic Case Studies in Psychotherapy, http://pcsp.libraries.rutgers.edu

Volume 7, Module 4, Article 3, pp. 449-476, 12-12-11 [copyright by author]

that the therapist might respond to the patient's contribution by saying, for example, "How do you feel at those times when you're not in a session or a meeting and you get ideas that seem like good ones?", or "What's it like to go from thinking you've got good ideas to thinking that they aren't good after all?” These responses convey empathic understanding because they communicate interest in the patient's experience. They also confirm the patient as ok as is because they implicitly indicate that (a) the therapist can readily imagine someone feeling the way the patient describes (i.e., that her experience doesn't seem strange to him or a reason for alarm), (b) that he is quite ready to believe that the patient sometimes thinks she has good ideas, and (c) that the therapist sees the patient as someone who can grapple with a difficult issue (i.e., the fact that although she thinks she has good ideas when she is by herself, she loses confidence in those ideas when she is with others).

By contrast, of course there simply is no occasion in the actual interaction for the therapist to make either of the two example responses I just suggested because the patient doesn't offer the particular hypothetical contribution we are considering. More importantly, in the actual interaction, the patient doesn't offer any contributions that really constitute expressing/showing herself and, therefore, she makes it quite unlikely that the therapist will respond to her in any ways that - although they might differ in content from the two example therapist responses - show empathic understanding for the patient or confirm her as ok as is.

\section{Tenet 8}

Tenet 8 puts forward a claim about another aspect of the costs of behaving defensively. Defensive interpersonal behavior patterns reduce the likelihood that feared consequences will occur (this is tenet 6) but, according to tenet 8, they also make it more likely that certain negative outcomes will occur that are distinct from an individual's key feared consequences.

As I explained earlier, when a person pursues wished-for responses in an interaction, this opens up the possibility that responses they fear might occur instead. Defensive behavior patterns represent attempts to negotiate such conflicts by pursuing wished-for outcomes in ways that attempt to "cancel out" the possibility that the feared consequences will take place. This cancelling out succeeds in the sense that defensive patterns make it unlikely that the feared outcome will occur (again, this is tenet 6). However, none of the parts of the "package" of behaviors included in the defensive pattern can be cancelled out as if they never took place. The package of pursuing a wish while also, in a sense, trying to cancel out that pursuit itself affects how the other person will respond. This leads to the feed-forward effects asserted in tenet 8 (and to other feed-forward effects predicted in tenet 9, as we will see later).

The session segment provides support for this tenet about feed-forward effects. As I have explained, the patient attempted to negotiate the conflict between her wish to be shown empathic understanding and to be confirmed as ok as is and her fear of being ignored and neglected by putting forward individual points or alluding to significant feelings but not following through. As we saw when we considered tenet 6 , this works against the therapist ignoring/neglecting her because, although she does something like expressing/showing herself (by putting forward 
Defenses in Interpersonal Interaction: Using a Theory-Building Case Study to Develop and Validate the Theory of Interpersonal Defense

M.A. Westerman

Pragmatic Case Studies in Psychotherapy, http://pcsp.libraries.rutgers.edu

Volume 7, Module 4, Article 3, pp. 449-476, 12-12-11 [copyright by author]

individual points or making allusions), she never really expresses/shows herself (because she only puts forward individual points or makes allusions and does not follow through with them). However, although the pattern cancels out some of the effects of the patient's attempts to pursue her wish, those attempts themselves remain part of the pattern. They do not disappear. The patient never really expresses/shows herself, but she does repeatedly put forward individual points and make allusions. The whole package of the patient's behavior pattern affects the therapist and that package consists of behaviors in which the patient does something like showing/expressing and not following through. Moreover, the parts of this oscillation do not mesh well - she fails to follow through after putting forward individual points even when there is reason to believe that she could add something to her initial remark, and she raises new points when the therapist tries to help her move ahead with some point she herself put forward a moment before.

In the session segment, the therapist responds to the patient as someone who makes it difficult for him to get to know who she is, what she thinks, how she feels, and so forth. In more common clinical terms, we can say that he responds to her as someone who is behaving in a hostile submissive, provocative manner. For his part, the therapist takes a controlling, hostile stance toward her, trying to get her to express/show herself. He interrupts her (turns 2, 4, 6, 10), tells her how to complete her points (turns 2, 4, 6, 10), “chides” her (turns 2, 10), “corrects” her (turn 10), and behaves in a smug, condescending manner (turns 2, 4, 8, 10). In SASB terms, he intrudes, blocks, restricts the patient (137), puts her down and acts superior (136), and accuses/blames her (135).

The therapist does not behave in the ways the patient fears (which, again, would be to neglect her (125) or ignore her (126)), but his behavior toward her certainly includes negative consequences. Furthermore, we can see how the patient's defensive pattern contributes to the therapist behaving in this particular unfortunate manner.

\section{$\underline{\text { Tenet } 9}$}

When I discussed tenet 7, I maintained that although defensive interpersonal patterns include attempts to pursue an individual's wished-for outcomes, they also work to cancel out the effects of those attempts and, as a result, they actually make it unlikely that wished-for relationship events will occur. However, I should point out again, as I did when we considered tenet 8, that while defensive patterns cancel out some of the effects of pursuing the wish, the attempts to realize the wish do not disappear. The whole package of the person's behavior includes those attempts and also the efforts to cancel out their ramifications. The entire package affects how the other person will respond. According to tenet 9, defensive behavior leads to particular positive outcomes, although these outcomes are different from the individual's key wished-for outcomes. Therefore, the benefits of defensive interpersonal patterns include promoting certain positive outcomes that are distinct from the person's wish as well as avoiding feared outcomes. 
Defenses in Interpersonal Interaction: Using a Theory-Building Case Study to Develop and Validate the Theory of Interpersonal Defense

M.A. Westerman

Pragmatic Case Studies in Psychotherapy, http://pcsp.libraries.rutgers.edu

Volume 7, Module 4, Article 3, pp. 449-476, 12-12-11 [copyright by author]

Note that according to interpersonal defense theory, the feed-forward effects of defensive interpersonal patterns include both certain negative consequences that are distinct from the individual's key fear (as per tenet 8) and particular positive outcomes that are distinct from the individual's key wish (as per tenet 9). The theory predicts that when a person behaves defensively, the other person will behave in particular positive and negative ways. These feedforward effects may appear at different times in the other person's behavior or they may occur simultaneously as different aspects of the other person's behavior in the same sample of interaction. The session segment provides support for tenet 9 in addition to tenet 8 . It is an example of the other person's behavior (in this case, the therapist's behavior) having both positive and negative aspects in the same sample of interaction.

Let me note again that the full package of the patient's defensive pattern includes oscillations between doing something like expressing/showing herself by putting forward individual points or making allusions and not following through. As I said previously, this leads the therapist to respond to the patient as someone who makes it difficult for him to get to know who she is, what she thinks, how she feels, and so forth. In part, this leads him to try to get her to express/show herself (which leads to the negative outcomes predicted in tenet 8), but it also leads him to try to help her. In fact, in certain respects, he responds to the patient in a benign, managing manner. He tries to guide her towards expressing/showing herself and he also takes her off the hook when expressing/showing herself might be especially difficult. In SASB terms, he constructively stimulates (145), benevolently monitors, reminds (147), and specifies what's best (148), and he also pampers, overindulges the patient (146).

We see the therapist trying to guide the patient by specifying what's best (148) when, in turn 4, he encourages her to finish the point she began in turn 3. The therapist's question in turn 6, “Are there things I'm doing that are contributing to that feeling of pressure?”, offers constructive stimulation (145) by suggesting a particular direction the patient could take to follow up on her comment in turn 5 about feeling pressured. The therapist's contribution in turn 10 captures several aspects of his positive stance towards the patient. By reminding (147) the patient about something he does that may lead her to feel pressured, he provides her with an example that might help her respond to the question he posed in turn 6 . When the therapist goes on in turn 10 to add "Are there other things that I that you can think of that I do that, you know, make it difficult for you?”, he uses constructive stimulation (145) once again to suggest a direction the patient could take to answer his question. But the therapist's response in turn 10 also works to take the patient off the hook, which in SASB terms would be pampering, overindulging the patient (146), because he suggests that she might feel pressured when he asks her to finish her sentences. With this comment, he offers an answer to his own question that the patient might find especially difficult to mention.

These positive aspects of how the therapist behaves toward the patient are quite different from her wished-for outcomes of being shown empathic understanding and being confirmed as ok as is. (The figure showing the SASB model is helpful here because it visually represents the differences between the patient's wish and the particular positive outcomes that her pattern actually promotes). Nevertheless, there is a sense in which the way the therapist behaves is 
Defenses in Interpersonal Interaction: Using a Theory-Building Case Study to Develop and Validate the Theory of Interpersonal Defense

M.A. Westerman

Pragmatic Case Studies in Psychotherapy, http://pcsp.libraries.rutgers.edu

Volume 7, Module 4, Article 3, pp. 449-476, 12-12-11 [copyright by author]

positive and, therefore, a benefit that results from the patient's defensive pattern. Furthermore, we can see how the patient's interpersonal behavior pulls for this particular stance on the therapist's part while it also works against realizing her key wish - even though she behaves in a way that includes repeated attempts to realize her wish.

\section{Persistence of Problematic Interpersonal Behavior Patterns}

The tenets about the feed-forward effects of defensive patterns provide a novel response to the longstanding issue about why dysfunctional processes persist. The key point here goes back to Freud's insight, which I referred to in the beginning of this article, that although defensive processes actually lead to psychological problems, individuals employ them in the attempt to prevent dreaded outcomes from occurring. But just how does this work?

Many theorists, clinicians, and psychotherapists have tried to explain this insight in terms of the self-fulfilling prophecy concept, the notion that some individuals attempt to avoid feared outcomes in ways that result in promoting those very outcomes (Downey, Freitas, Michaelis, \& Khouri, 1998; Hilton, Darley, \& Fleming, 1989; Wachtel, 1994, 1997, 2008). According to this idea, efforts of this sort by an individual are dysfunctional, but they are maintained because they are aimed at avoiding feared outcomes (notwithstanding the fact that they actually lead to those consequences). I believe Wachtel's $(1994,1997,2008)$ “vicious cycle” explanation is the most compelling of these models but, like other ideas along this vein, it rests on the paradoxical idea that people continue to behave in ways that lead to their fears because they are trying to avoid their fears.

Interpersonal defense theory offers a different account. Furthermore, it provides a more detailed analysis of the relevant processes as compared to ideas based on the self-fulfilling prophecy concept. I agree with Wachtel (2008) that there is an irony at the heart of psychopathology, but the phenomena are not ironic in the sense that they are based on efforts to avoid feared outcomes that lead to those very consequences. As we have seen, according to tenet 6, defensive interpersonal patterns enable people to successfully avoid the outcomes they fear. Nevertheless, there is an irony at the heart of defensive patterns because a person's efforts to protect him- or herself do make things worse. There are significant costs associated with behaving defensively, as the full set of tenets about feed-forward effects makes clear. Specifically, the costs include making it unlikely that the person will realize his or her wishes (tenet 7) and promoting certain negative consequences (tenet 8). For many - indeed, most people who behave defensively, these costs are worse than the outcomes the individual fears, especially because it is often the case that if the person were to behave nondefensively, his or her fears would not, in fact, occur in many relationship contexts, whereas, by engaging in defensive patterns, the person makes it quite likely that he or she will suffer the costs of behaving in that manner.

Why do people persist in behaving defensively given that they are so costly? As compared to the self-fulfilling prophecy notion, interpersonal defense theory makes it much easier to understand what maintains dysfunctional processes. To begin with, people continue to 
Defenses in Interpersonal Interaction: Using a Theory-Building Case Study to Develop and Validate the Theory of Interpersonal Defense

M.A. Westerman

Pragmatic Case Studies in Psychotherapy, http://pcsp.libraries.rutgers.edu

Volume 7, Module 4, Article 3, pp. 449-476, 12-12-11 [copyright by author]

behave defensively because their defensive patterns make it possible for them to avoid the key negative consequences they fear. In addition, people continue to engage in defensive patterns in the attempt to realize their wishes, because those patterns include efforts aimed at pursuing wishes, albeit efforts that are actually quite limited in their nature and effectiveness. Another important point here is that although the costs of behaving defensively include negative outcomes - indeed, negative consequences that have become all too familiar to the individual those consequences are not the most salient negative consequences for the individual. Hence, they do not have the same impact as would occurrences of the key feared outcome. Finally, as postulated in tenet 9, defensive behavior leads to positive outcomes that, although different from an individual's key wish, constitute other benefits of behaving defensively (in addition to avoiding feared outcomes) that contribute to maintaining the problematic patterns.

\section{LOGIC OF THEORY VALIDATION}

The analysis of the session segment provides support for interpersonal defense theory. As compared to the hypothesis-testing studies I previously conducted on different parts of the theory, which I mentioned earlier in this paper, the analysis presented here based on the theorybuilding case study approach offers a clearer picture of the processes of interest because we examined those processes quite closely in context. In addition, the analysis of the session segment illustrates how the theory-building approach offers a method for determining whether multiple tenets of a theory are simultaneously supported by a set of observations from a single case. The fact that our consideration of the segment of interaction supported the set of tenets constitutes a compelling kind of support for the theory.

Of course, an analysis of any small sample of behavior can only go so far toward demonstrating a theory's validity. As I said at the outset of the analysis, before we can place confidence in the theory, we would have to compare the tenets to other observations from the same case and from other cases as well.

There is another point about the logic of theory validation that is at least as important to consider. So far, I have discussed the process of comparing theoretical tenets to observations as if it involves two elements (tenets and observations). Other accounts of the theory-building case study approach also have described the process in this way (Stiles, 2003, 2007, 2009). Our consideration of the session segment, however, actually involved three elements because comparing observations to the tenets required understanding what was occurring at each point in the interaction (i.e., the observations) in terms of the case formulation. This was true when we had to recognize how the patient's behavior related to her wish and fear and also when we considered whether the patient's behavior was characterized by a particular recurring noncoordinating pattern.

These remarks indicate that the logic of how case observations provide support for a theory's tenets actually is quite complicated. Investigators cannot consider independently the three elements that play roles in the process of theory validation. Instead, formulations are arrived at based on data and theoretical tenets. Moreover, for analyses based on interpersonal 
Defenses in Interpersonal Interaction: Using a Theory-Building Case Study to Develop and Validate the Theory of Interpersonal Defense

M.A. Westerman

Pragmatic Case Studies in Psychotherapy, http://pcsp.libraries.rutgers.edu

Volume 7, Module 4, Article 3, pp. 449-476, 12-12-11 [copyright by author]

defense theory in particular, formulations of wishes and fears, on the one hand, and the noncoordinating pattern, on the other, are arrived at in tandem, not separately from each other. I believe that these points apply to any theory-building case study of any theory. Even if the theory doesn't expressly refer to a "formulation," the theory-building analysis will require this third element for making comparisons between theoretical tenets and observations. For example, theory-building case studies of Stiles's (2002) assimilation model require identification of a given patient's different "voices," and, furthermore, I imagine it is the case that arriving at characterizations of voices that are in conflict with each other involves considering those voices in tandem, not independently.

Where does this leave us? Although these considerations indicate that the process of theory validation is complicated, they do not lead to the conclusion that the process necessarily is circular. Theory-building case study analyses can provide compelling support for a theory so long as investigators keep in mind the roles played by the three elements and proceed accordingly. In order to do so, they need to first determine whether it is possible to arrive at a formulation that is well-supported by a given set of observations from a particular case. Ideally, the formulation should also be based on other data about the case besides observations of therapy sessions (e.g., information about early childhood history if that is relevant to the kind of formulation called for by the theory under consideration). Investigators can then use that formulation to determine whether the initial set of observations of therapy process supports the theoretical tenets under consideration. At this point, potential support for the tenets is limited at best given the lack of independence between the relevant elements. However, an investigator can then go on to determine whether additional observations of therapy process offer further support for the theoretical tenets using the formulation arrived at in the initial step to make possible the new comparisons between observations and tenets. One problem that might come up at this step is that new observations may indicate that that the initial formulation is not quite right. If that happens, it is necessary to modify the original formulation. In this situation, the investigator would have to repeat the process to determine whether additional new observations support the tenets using the modified formulation as the basis for making those comparisons. It also would be necessary to go back to the first set of observations to make sure that they support the tenets given the modified formulation. If applicable to the theory, it also is quite useful to use the formulation to compare tenets to data about the case other than observations of therapy process, as I did earlier when I considered the patient's relationship with the man she met at an adult education class. Once all of these steps have been taken, if the process suggests that the tenets are valid, then the investigator can go on to repeat the entire procedure with new observations from other cases (which will involve arriving at a formulation for each case plus all the other steps).

If this entire process is followed and the different sets of observations fit the tenets, then the process does provide strong support for the theory. Although it goes well beyond the scope of the present article, I can simply note here that taken in toto the multiple case study project provided the kind of support just described for the tenets we considered here in the context of one session segment. Of course, specific features differed from case to case (the nature of the recurring noncoordinating pattern, the key wishes and fears, the positive outcomes other than the 
Defenses in Interpersonal Interaction: Using a Theory-Building Case Study

to Develop and Validate the Theory of Interpersonal Defense

M.A. Westerman

Pragmatic Case Studies in Psychotherapy, http://pcsp.libraries.rutgers.edu

Volume 7, Module 4, Article 3, pp. 449-476, 12-12-11 [copyright by author]

wish that are promoted by the noncoordinating pattern, the negative outcomes other than the fear that are promoted by the pattern), but each case supported the tenets.

\section{THEORY DEVELOPMENT}

The theory-building case study approach can contribute to developing as well as validating theories. Investigators employing the approach sometimes discover that observations from a case point to the need to refine, revise, or elaborate upon a theoretical tenet or to add a new tenet to the theory under investigation. They then can proceed to validate the new ideas by following steps similar to those described above. In such situations, researchers should determine first whether the revised or new tenet fits with observations previously considered from the case at hand. Next, they should examine new observations from that case to see if those observations also support the new or revised ideas. Finally, the investigators should go on to follow the entire process outlined in the previous section to see if the revised or new tenet as well as the theory's other tenets are supported by new cases.

My work on the multiple case study project led to several changes in the theory of interpersonal defense. One of those changes concerns the parts of the theory that are the subject of this article. I will discuss that change to illustrate the process of theory development. My remarks also will serve to add another substantive point about interpersonal defense theory to what I have said so far.

Before I turn to that change in the theory, I should note that my work on the multiple case study project differed from my previous efforts on interpersonal defense theory in that I employed SASB for that project. Although using SASB did not constitute changing interpersonal defense theory per se, it offered a particular vocabulary that brought added clarity to the ideas I was investigating. This was especially true with regard to tenets 8 and 9 , which concern how defensive behavior patterns feed forward to promote positive and negative outcomes that are different from the person's key wishes and fears. In the SASB system, the sense in which those outcomes differ from the main wish and fear becomes very clear because they lie at different points on the circumplex (the positive outcomes are located on the right hand side of the circumplex, as is the case for the wish, but at different specific points than the wish for the particular person in question; the negative outcomes lie on the left hand side of the circumplex, like the fear, but they are located at different specific points than the fear for the person in question). I can note that examination of the full set of cases in the multiple case study project indicated that SASB offers a helpful language for working with the concepts of interpersonal defense theory.

To turn to the change in the theory I referred to above: As I noted much earlier in this article, according to the original version of tenet 4 , defensive interpersonal behavior patterns include elements aimed at realizing the wish and other elements that are attempts to make impossible feared consequences that might occur as the result of pursuing the wish. The idea that defensive interpersonal patterns include these two elements continues to be part of the theory, but my analysis of the session segment as well as other material from that case and the other 
Defenses in Interpersonal Interaction: Using a Theory-Building Case Study to Develop and Validate the Theory of Interpersonal Defense

M.A. Westerman

Pragmatic Case Studies in Psychotherapy, http://pcsp.libraries.rutgers.edu

Volume 7, Module 4, Article 3, pp. 449-476, 12-12-11 [copyright by author]

cases in the multiple case study project led me to revise the tenet so that it no longer links specific elements of the pattern to pursuing the wish and different elements of the pattern to avoiding the fear.

I changed tenet 4 by reformulating it in two parts. According to tenet $4 a$, defensive patterns are structured in such a way that they aim at realizing an individual's wish while they also attempt to make impossible feared consequences that might occur as the result of pursuing the wish. This part of the tenet no longer makes any reference to the elements of defensive patterns, but simply asserts that, overall, those patterns aim at pursuing wishes and avoiding fears. Earlier, I showed that the session segment we have been considering provides support for tenet 4a. Tenet 4a also was supported by other observations from that case and by the other cases in the multiple case study project.

Tenet 4b maintains that defensive patterns are made up of two elements, one that consists of attempts to pursue the wish and another that includes attempts to avoid feared consequences that might result from pursuing the wish, but it differs from the original version of tenet 4 in one respect. Before presenting 4b, however, I will summarize ideas related to those two elements that were part of my analyses of the session segment in connection with the feed forward tenets (tenets 6-9). Recall that those analyses were based on identifying two components of the patient's pattern, one that included attempts to pursue her wish by putting forward individual points and making allusions, and another that consisted of ways in which the patient did not follow through in order to avoid feared outcomes that might result from pursuing her wish. My analyses also rested on understanding that these elements play a complicated set of roles with regard to feed-forward effects as a result of how each element relates to the context of the overall pattern of behavior. I showed that the feed-forward effects of the pursues wish element are not limited to whether the wish is realized and that the feed-forward effects of the avoids fear element are not limited to whether feared outcomes occur. Instead, each of these elements play roles regarding the patient's wish and fear and also regarding positive outcomes that are different from the wish and negative outcomes that are different from the fear. ${ }^{6}$

\footnotetext{
${ }^{6}$ Specifically, I showed that the pursues wish element (1) represents attempts by the patient to pursue her wish of being shown empathic understanding and confirmed as ok as is by expressing and showing herself, (2) that, in a sense, this element works to avoid the patient's fear because the points she puts forward are only individual points and the allusions she makes are not developed and, therefore, the patient does not really express/show herself and open up the possibility of her feared outcome, (3) that, although the patient's bids at expressing/showing herself are not developed, their presence in her pattern of behavior makes a difference such that, as part of the package of her overall pattern, it promotes the occurrence of positive outcomes that are different from her wish (the other person acts towards her in a benignly managing way trying to help her express/show herself), and (4) as part of her overall pattern, the pursues wish element also contributes to promoting negative consequences that are different from the patient's fear (the other person behaves towards her in a hostile controlling manner trying to get her to express/show herself). With regard to the avoids fear element, I showed that (1) the patient attempts to avoid her fear of being ignored and neglected by not following through, which "cancels out" some of the possible effects of her bids to express/show herself, (2) that by cancelling out those possible effects of the
} 
Defenses in Interpersonal Interaction: Using a Theory-Building Case Study to Develop and Validate the Theory of Interpersonal Defense

M.A. Westerman

Pragmatic Case Studies in Psychotherapy, http://pcsp.libraries.rutgers.edu

Volume 7, Module 4, Article 3, pp. 449-476, 12-12-11 [copyright by author]

Although tenets 6 through 9 are based on recognizing that the roles played by the two elements that make up defensive interpersonal behavior patterns depend on their location in the context of the exchange in which they occur, during the course of my work on the multiple case study project, I gained a greater appreciation of the thoroughly indexical nature of the parts of defensive patterns. That understanding led me to revise the original version of tenet 4 by including a new part, 4b. According to tenet $4 \mathrm{~b}$, for analytical purposes, we can say that defensive interpersonal patterns are made up of two parts, an element aimed at realizing the wish and an element that attempts to make impossible feared consequences that might occur as the result of pursuing the wish. A given concrete turn in an interaction, however, sometimes simultaneously plays both roles. Tenet $4 \mathrm{~b}$ is based on the idea that when we examine defensive behavior patterns it is always possible to identify a part of the pattern that plays the role of pursuing the person's wish and that if we then turn to a subsequent point in the exchange, we can identify another part of the pattern that attempts to avoid feared consequences that might occur as a result of pursuing the wish. Not always, but in many cases, however, if we consider how a given concrete occurrence of the element of the pattern that pursues the wish relates to what came before it, we find that the concrete bid in question also plays the role of avoiding feared outcomes that might result from a previous attempt at pursing the wish. Hence, it plays a double role.

The session segment provides support for this new part of tenet 4. Again, the patient's defensive interpersonal pattern includes a pursues wish element that consists of putting individual points on the table and making allusions and an avoids fear element that consists of different ways in which she does not follow through. As I noted earlier, one of the ways she does not follow through on some point she made earlier is by putting forward a new point or alluding to something other than her prior point. Therefore, when it comes to certain patient turns in the exchange, we have to recognize that a particular contribution constitutes an instance of the avoiding fear element - because it provides a way to not follow through on a previous topic and that it also constitutes an occurrence of the pursues wish element - because looking forward from this juncture in the exchange, we see that it represents an attempt to express/show herself. We encountered this phenomenon when we considered turn 5 of the session segment. In that turn, the patient derails discussion of the topic that was on the table (how she does not like the way she is in therapy) by saying something about another issue (how she feels pressured by the therapist).

patient's bids to express/show herself the avoids fear element also works against the patient realizing her wish, (3) that although the avoids fear element cancels out some of the effects of the patient's bids to express/show herself, those bids are still part of the overall pattern and, as a result, not following through contributes to negative outcomes that are different from the patient's fears (again, the other person behaves toward the patient in a hostile controlling manner trying to get the patient to express/show herself), and (4) as part of the overall pattern, the avoids fear element also contributes to positive outcomes that are different from the patient's wish (again, the other person acts towards her in a benignly managing way trying to help her express/show herself.) 
Defenses in Interpersonal Interaction: Using a Theory-Building Case Study

to Develop and Validate the Theory of Interpersonal Defense

M.A. Westerman

Pragmatic Case Studies in Psychotherapy, http://pcsp.libraries.rutgers.edu

Volume 7, Module 4, Article 3, pp. 449-476, 12-12-11 [copyright by author]

Note that only some concrete turns in the exchange play this double role. For example, at times, the patient "trails off" as a way of not following through, that is, she speaks more slowly and ends an attempt to express a thought midstream with a long pause. We saw an example of this in the beginning of the session segment. In the first turn, the patient initiates the topic of how she doesn't like the way she is in therapy, but she trails off with long pauses in the remainder of that turn and also in turn 3. This appearance of the avoids fear element does not play a double role because it does not also serve as an attempt by the patient to pursue her wish by expressing/showing herself.

The multiple case study project offered further support for tenet 4b. In addition to the support offered by the session segment considered in this article, other observations from that case included examples of concrete contributions by the patient that play a double role. Examination of the other cases offered additional support. Although the patients' defensive patterns are quite different in each of those other cases and very different behaviors make up the pursues wish and avoids fear elements, in each case, the defensive patterns are made up of a pursues wish element and an avoids fear element and certain concrete contributions by each of the patients play a double role.

\section{CONCLUDING REMARKS}

In this article, I closely examined patient-therapist interaction during a psychotherapy session to pursue two objectives. My first goal concerned substantive matters regarding the theory of interpersonal defense. One part of that goal was determining whether analysis of the session segment would provide support for a number of the tenets of interpersonal defense theory. My first objective also included clarifying previous presentations of the theory (Westerman, 1998; Westerman \& Steen, 2007, 2009) by showing how the theory applies to clinical material examined in context. My second goal was to illustrate the theory-building case study approach and to offer some points about the logic of theory validation.

With regard to the first objective, the analyses I have presented provided support for the tenets under investigation, although they pointed to the need to modify one of those tenets. Of course, examining a small sample of behavior can only lead to a small increment of confidence in a theory, but the results of the careful analyses of clinical phenomena in context presented here constitute a significant addition to findings from previous nomothetic studies of different parts of interpersonal defense theory.

The analyses I have offered also help clarify how interpersonal defense theory, as compared to previous theoretical work on defense processes, shifts from focusing on intrapsychic mechanisms that try to regulate inner experience to interpersonal behavior patterns that attempt to influence what occurs in interpersonal relationships. This shift of focus leads to a new way of conceptualizing problematic interpersonal behavior. The close analysis of the patient's interpersonal behavior I have presented gives a good sense of what defensive interpersonal patterns with their recurring breaches of coordination are like. As I noted earlier, this approach to problematic interpersonal behavior has relevance for understanding transference 
Defenses in Interpersonal Interaction: Using a Theory-Building Case Study to Develop and Validate the Theory of Interpersonal Defense

M.A. Westerman

Pragmatic Case Studies in Psychotherapy, http://pcsp.libraries.rutgers.edu

Volume 7, Module 4, Article 3, pp. 449-476, 12-12-11 [copyright by author]

phenomena. It also provides a different way to study patients' contributions to the alliance (see Westerman \& Foote, 1995). My examination of the session segment also gives a good sense of the parts of interpersonal defense theory that concern how defensive behavior on the part of one individual feeds forward to affect how the other person in a relationship behaves. I discussed how these ideas lead to a new approach to countertransference, point away from common formulations of the self-fulfilling prophecy concept, and offer a novel approach to making sense of why dysfunctional processes persist.

To be sure, there is a need for further research on interpersonal defense therapy, but the present study coupled with previous investigations suggests that the theory holds promise as a way to address important issues. Although it goes well beyond the scope of this article, I should note once again that interpersonal defense theory also has implications for how therapists can contribute more effectively to successful therapy outcomes.

With regard to the second objective, which concerns the theory-building case study approach, I have demonstrated the process of simultaneously examining multiple tenets from a theory in the context of clinical material from a single case. I believe the results of the analyses I have presented illustrate how this process can lead to a compelling kind of support for a theory that is quite different from the type of support investigators might obtain from hypothesis-testing studies that examine one tenet of a theory at a time. In my remarks about the logic of theory validation in theory-building case study research, I highlighted the role played by case formulations in the process of determining whether observations conform to theoretical tenets and suggested how investigators should employ the theory-building approach in order to arrive at sound conclusions. My examination of the session segment also provided an opportunity for illustrating the process of revising a theoretical tenet. The present study suggests that the theorybuilding approach is a useful method for both validating and developing theories.

\section{REFERENCES}

Battle, C. C., Imber, S. D., Hoehn-Saric, R., Stone, A. R., Nash, E. R., \& Frank, J. D. (1966). Target complaints as criteria of improvement. American Journal of Psychotherapy, 20, 184-192.

Benjamin, L. S. (1979). Structural analysis of differentiation failure. Psychiatry: Journal for the Study of Interpersonal Processes, 42, 1-23.

Dahmen, B. A., \& Westerman, M. A. (2007). Expectations about the long-term consequences of recurring defensive interpersonal behavior. Journal of Research in Personality, 41, 10731090.

Dewey, J. (1896). The reflex arc concept in psychology. Psychological Review, 3, 357-370.

Downey, G., Freitas, A.L., Michaelis, B., \& Khouri, H. (1998). The self-fulfilling prophecy in close relationships: Rejection sensitivity and rejection by romantic partners. Journal of Personality and Social Psychology, 75, 545-560.

Heidegger, M. (1962). Being and time (M. Macquarrie \& E. Robinson, Trans.). New York, NY: Harper \& Row.

Hilton, J. L., Darley, J. M., \& Fleming, J. H. (1989). Self-fulfilling prophecies and self-defeating 
Defenses in Interpersonal Interaction: Using a Theory-Building Case Study to Develop and Validate the Theory of Interpersonal Defense

M.A. Westerman

Pragmatic Case Studies in Psychotherapy, http://pcsp.libraries.rutgers.edu

Volume 7, Module 4, Article 3, pp. 449-476, 12-12-11 [copyright by author]

behavior. In R. C. Curtis (Ed.), Self-defeating behaviors: Experimental research, clinical impressions, and practical implications. New York, NY: Plenum Press.

Horney, K. (1939). New ways in psychoanalysis. New York, NY: Norton.

Horney, K. (1945). Our inner conflicts. New York, NY: Norton.

Keenan, E. O., \& Schieffelin, B. B. (1976). Topic as a discourse notion. In C. Li (Ed.), Subject and topic (pp. 337-384). New York, NY: Academic Press.

Luborsky, L. (1984). Principles of psychoanalytic psychotherapy: A manual for supportiveexpressive treatment. New York, NY: Basic Books.

Merleau-Ponty, M. (1962). Phenomenology of perception (C. Smith, Trans.). London, England: Routledge \& Kegan Paul.

Muran, J. C., Safran, J. D., Samstag, L. W., \& Winston, A. (2005). Evaluating an alliancefocused treatment for personality disorders. Psychotherapy, 42, 532-545.

Pollack, J., Flegenheimer, W., Kaufman, J., \& Sadow, J. (1992). Brief adaptive psychotherapy for personality disorders: A treatment manual. San Diego, CA: Social \& Behavioral Documents.

Soldz, S. (1990). The therapeutic interaction. In R. A. Wells \& V. J. Giannetti (Eds.), Handbook of the brief psychotherapies (pp. 22-53). New York: Plenum Press.

Spitzer, R. L., Williams, J. B. W., Gibbon, M., \& First, M. B. (1990). Structured clinical interview for DSM-III-R - patient edition (with psychotic screen) - SCID-P (w/psychotic screen) - version 1.0. Washington, DC: American Psychiatric Press.

Stiles, W. B. (2002). Assimilation of problematic experiences. In J. C. Norcross (Ed.), Psychotherapy relationships that work: Therapist contributions and responsiveness to patients (pp. 375-365). New York, NY: Oxford University Press.

Stiles, W. B. (2003). When is a case study scientific research? Psychotherapy Bulletin, 38, 6-11.

Stiles, W. B. (2007). Theory-building case studies of counselling and psychotherapy. Counselling and Psychotherapy Research, 7, 122-127.

Stiles, W. B. (2009). Logical operations in theory-building case studies. Pragmatic Case Studies in Psychotherapy, Vol. 5(3), Article 2, 9-22. Available: http://hdl.rutgers.edu/1782.1/pcsp_journal

Strupp. H. H. (1980a). Success and failure in time-limited psychotherapy. A systematic comparison of two cases: Comparison 1. Archives of General Psychiatry, 37, 595-603.

Strupp. H. H. (1980b). Success and failure in time-limited psychotherapy: A systematic comparison of two cases: Comparison 2. Archives of General Psychiatry, 37, 708-716.

Strupp. H. H. (1980c). Success and failure in time-limited psychotherapy: With special reference to the performance of a lay counselor. Archives of General Psychiatry, 37, 831-841.

Strupp. H. H. (1980d). Success and failure in time-limited psychotherapy. Further evidence (Comparison 4). Archives of General Psychiatry, 37, 947-954.

Strupp, H. H., \& Binder, J. L. (1984). Psychotherapy in a new key: A guide to time-limited dynamic psychotherapy. New York, NY: Basic Books.

Sullivan, H. S. (1953). The interpersonal theory of psychiatry. New York, NY: Norton.

Wachtel, P. L. (1994). Cyclical processes in personality and psychopathology. Journal of Abnormal Psychology, 103, 51-54.

Wachtel, P.L. (1997). Psychoanalysis, behavior therapy, and the relational world. Washington, DC: American Psychological Association. 
Wachtel, P. L. (2008). Relational theory and the practice of psychotherapy. New York, NY: Guilford Press.

Watzlawick, P., Beavin, J. H., \& Jackson, D. D. (1967). Pragmatics of human communication: A study of interactional patterns, pathologies, and paradoxes. New York, NY: Norton.

Westerman, M. A. (1998). Reconceptualizing defense as a special type of problematic interpersonal behavior pattern: A fundamental breach by an agent-in-a-situation. Journal of Mind and Behavior, 19, 257-302.

Westerman, M. A. (2009). What can we learn from case studies? More than most psychologists realize. Pragmatic Case Studies in Psychotherapy, Vol. 5(3), Article 5, 53-70. Available: http://hdl.rutgers.edu/1782.1/pcsp_journal

Westerman, M. A., \& Foote, J. P. (1995). Patient coordination: Contrasts with other conceptualizations of patients' contribution to the alliance and validity in insight-oriented psychotherapy. Psychotherapy, 32, 222-232.

Westerman, M. A., Foote, J. P., \& Winston, A. (1995). Change in coordination across phases of psychotherapy and outcome: Two mechanisms for the role played by patients' contribution to the alliance. Journal of Consulting and Clinical Psychology, 63, 672-675.

Westerman, M. A., \& Prieto, D. M. (2006). Expectations about the short-term functional role played by defensive behavior in interpersonal interactions. Journal of Research in Personality, 40, 1015-1037.

Westerman, M. A., \& Steen, E. M. (2007). Going beyond the internal-external dichotomy in clinical psychology: The theory of interpersonal defense as an example of a participatory model. Theory \& Psychology, 17, 323-351.

Westerman, M. A., \& Steen, E. M. (2009). Revisiting conflict and defense from an interpersonal perspective: Using structured role plays to investigate the effects of conflict on defensive interpersonal behavior. Psychoanalytic Psychology, 26, 379-401.

Wittgenstein, L. (1958). Philosophical investigations (3rd ed.; G. E. M. Anscombe, Trans.). New York, NY: Macmillan. 
to Develop and Validate the Theory of Interpersonal Defense

M.A. Westerman

Pragmatic Case Studies in Psychotherapy, http://pcsp.libraries.rutgers.edu

Volume 7, Module 4, Article 3, pp. 449-476, 12-12-11 [copyright by author]

\section{Figure 1. Structural Analysis of Social Behavior (SASB).}

(Note that the figure omits the introject surface and includes only the two interpersonal surfaces of the SASB model. From Benjamin, L.S. (1979). Structural analysis of differentiation failure. Psychiatry: Journal for the study of interpersonal processes, 42, 1-23. Reprinted with permission of The Guilford Press.)

\section{INTERPERSONAL}

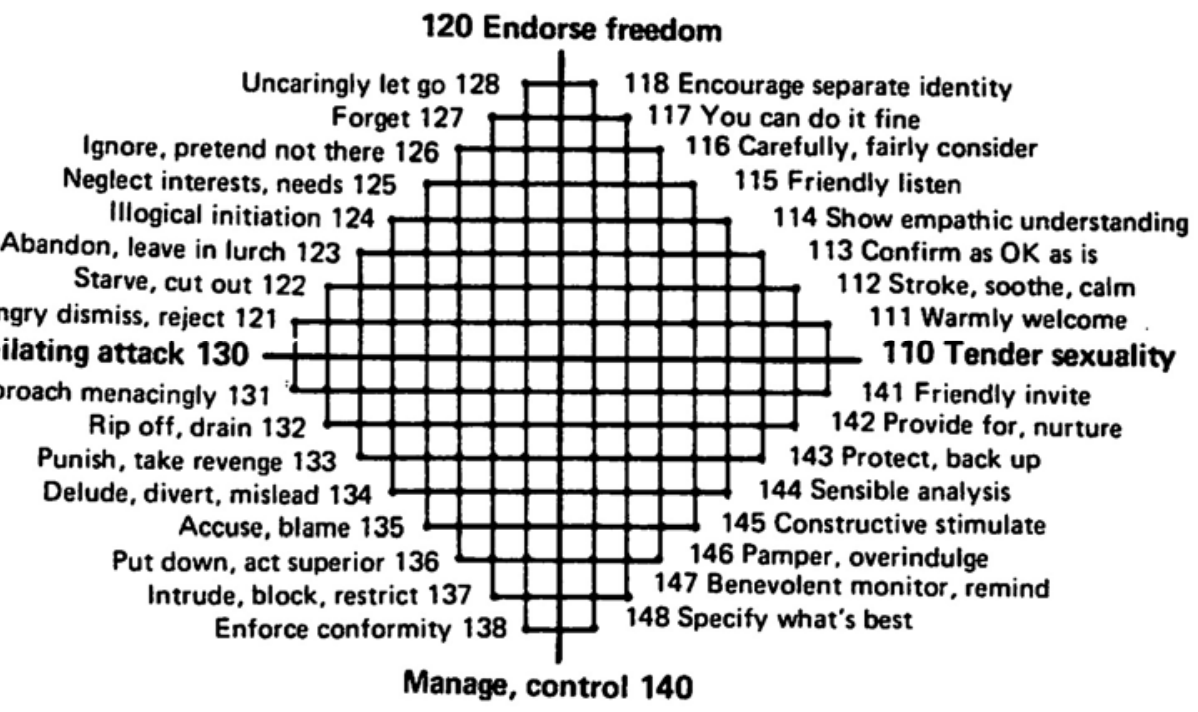

\section{SELF}

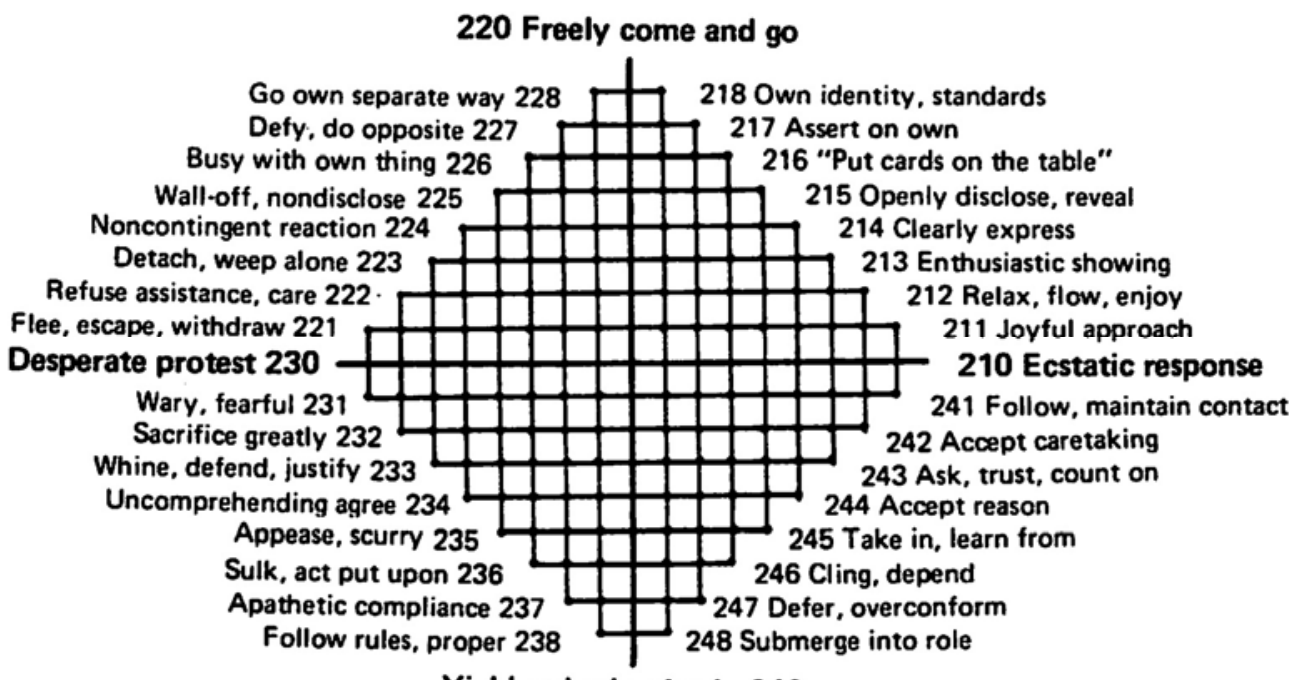

Yield, submit, give in $\mathbf{2 4 0}$ 